\title{
Experimental Study of Temperature Fluctuation Rule in Piston of CNG Engine
}

\author{
Zhiyong Zhang ${ }^{1, a^{*}}$, Yuhao Zhou ${ }^{2, b}$ and SiwenWang ${ }^{3, c}$ \\ 1,2,3No.2 Xiyuan 9 Road, Xihu District, Zhejiang, Hangzhou, China \\ azhiyong-zhang@chder.com, ${ }^{b}$ Yuhao-zhou@chder.com, c siwen-wang@chder.com
}

Keywords: temperature measurement; error calibration; piston; CNG engine

Abstract. In this study, a measurement system is developed for obtaining continuous piston temperatures in working engine by using a voltage recorder. In this paper, authors discuss the sensor package impact of test results in temperature measurement, and measured the piston temperature when the CNG engine was at speed of 1100rpm, 1200rpm, 1300rpm, 1500rpm, 1700rpm and 1900rpm, the oil/water temperature steady.

\section{Introduction}

Piston is one of the main heated components of internal combustion engine, and its reliability has important influence on the lifetime, reliability, emission performance and economy of the internal combustion engine. A working piston is usually characterized by its big heated area and poor lubricating condition, as in [1]. In addition, the heat load-induced problem of a piston becomes more and more serious as the strength degree of the engine increases. As alternative fuels (i.e. natural gas) emerge, the oxides of those impurities such as $\mathrm{S}$ and $\mathrm{P}$ that contained in the alternative fuels result in piston corrosion in high temperature. Since piston is reciprocating fast, it is very difficult to measure its temperature as in [2]. In general, previous piston temperature measurement systems and techniques can be categorized into two types: one is thermal plug, which is made by special alloy with a low melting point. The technique that uses thermal plug to measure the piston temperature is simple yet not accurate. The other type is thermocouple.

Thermocouple has higher measurement accuracy; however, the acquisition of those measurement data from inside of the internal combustion engine is very complex, as in [3]. The most common methods to acquire the measurement data are contact point method, induction coil method, RF telemetry method and carrying linkage, all of which have complex mechanisms and limited reliabilities, as in [4].

Therefore, the purpose of this study is to develop a piston temperature measurement system that can accurately, reliably and continuously measure the piston temperature, and both the acquisition of the measurement data and system installation should be easy, as in [5]. In order to achieve so, this study takes advantages of both the thermal plug and thermocouple. The thermocouple is used as the temperature measurement sensor and a voltage recorder is used to store the acquired measurement data from the thermocouple. Since this voltage recorder is attached to the piston, there is no relative movement between the recorder and the piston; therefore, this feature makes the system more reliable and easy for measurement data acquisition.

Authors used thermocouple as the sensor, and the data of thermocouple was written in voltage memory. The system of the temperature measurement didn't need carrying linkage and it had the advantages of two kinds of the piston temperature measurement.

\section{System Design of Piston Temperature Measurement}

The developed piston temperature measurement system consists of seven components: multiple thermocouples, a temperature-based triggering switch, an analog switch circuit, a compensate circuit, a voltage recorder, a thermal-insulating box, and the fixture. In order to easily assemble the measurement system with the piston, the dimension of the system is designed as small as possible. The 
thermocouple sensor is a $\mathrm{K}$ type thermocouple. The voltage recorder is integrated in a circuit board while the other components are integrated in another circuit board and two boards are installed under bottom of the piston boss pin socket. The schematic configuration of the developed measurement system was shown in Fig.1.

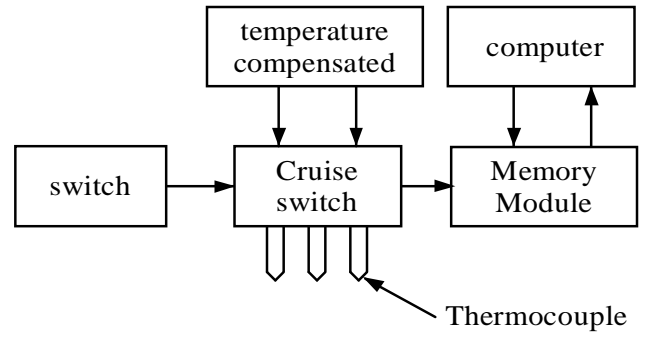

Fig. 1. Schematic of the designed measurement system

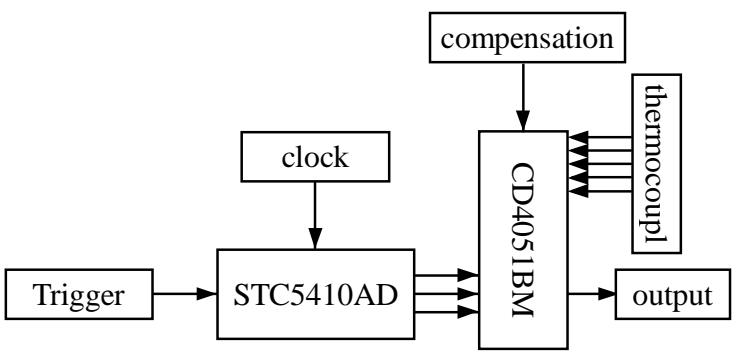

Fig.2. Schematic configuration of the developed the cruise module

The compensation circuit based on bridge compensation is designed to compensate the temperature measured by thermocouple when ambient temperature is lower than $150{ }^{\circ} \mathrm{C}$. The voltage signal of $\mathrm{V}_{\mathrm{x}}$ for the $\mathrm{Pt}_{1000} \neg$ resistance and the voltage signal of $\mathrm{V}_{1000}$ for another resistance $\mathrm{R}_{1000}$ were recorded and used to compensate the temperature $\mathrm{Tx}$ measured by the $\mathrm{Pt}_{1000}$ sensor, the equation for compensation temperature was in Eq. 1 . When the temperature of the piston measured, $\mathrm{Vx}$ and $\mathrm{V}_{1000}$ were written in the voltage memory

$$
T_{x}=\frac{V_{x}-V_{1000}}{V_{1000}} \times 260
$$

. The cruise switch circuit module consists of three parts: temperature switch, analog switch circuit, and compensate circuit. When the ambient temperature is below $45^{\circ} \mathrm{C}$, the temperature switch turns off and the analog switch circuit is in a stand-by state. When the ambient temperature is higher than $45^{\circ} \mathrm{C}$, the analog switch circuit starts to work. In this way, the designed cruise switch circuit that has a battery capacity of 750mAh can save power and have adequate time for engine bench test.

The temperature switch consists of a NTC thermistor and a comparator LM139. When the resistance of the thermistor decreases below $18 \mathrm{k} \Omega$ as the ambient temperature rises, STC54C10AD is triggered and CD4051 starts to work, therefore the cruise switch functions. CD4051 is controlled by the STC54C10AD program in order to activate the connected 8 channels in a proper order when the temperature signals are written into the voltage recorder. As a result, the measurement data in the recorder is stored as a regular cycle of 8 data sets. The schematic configuration of the developed the cruise module is shown in Fig.2.

The memory module used in this study has several features as follow: (1) five different reading-writing cycle times such as $0,25 \mathrm{~s}, 0.5 \mathrm{~s}, 1 \mathrm{~s}, 2 \mathrm{~s}$ and $5 \mathrm{~s}$; (2) a storage capacity of 1000000 sets of data; (3) a clock function; (4) controllable through R232 serial interface; (5) automatic overflow when memory is full.

Memory module was constituted from the power supply, voltage regulator chips, microcontrollers, memory chips, digital-analog converter chips. power supply was a lithium battery with $3.6 \mathrm{~V}$ voltage. Voltage resolution of the memory module is $\pm 5 \mu \mathrm{V}$. Microcontroller is the controller, with controlling each recording data sequentially written from the beginning dress of the memory page, and the next page was written when a page was written fully. The literacy program of memory module was simple and reading and writing program interface is user-friendly. A single cycle of the recorded data is shown in table1. and the diagram of memory module was shown in Fig.3.

\section{Error Calibration of Measurement System}

The calibration process is performed after the measurement system is heated in an oven at the temperature of $130^{\circ} \mathrm{C}$ for 60 minutes. A potentiometer is used to replace the output of thermocouples. The output voltage signal varies from $4.92 \mathrm{mV}$ to $9.75 \mathrm{mV}$ with a step of $0.2 \mathrm{mV}$. This equals to the 
temperature changing from $120^{\circ} \mathrm{C}$ to $240{ }^{\circ} \mathrm{C}$ with a step of $5^{\circ} \mathrm{C}$. The systematic error is shown in Fig.4. The stable systematic error validates the effectiveness of the thermal-insulating box, which in turn results in a stable measurement. It can also be observed that the measurement error is around $\pm 1{ }^{\circ} \mathrm{C}$ when the systematic error is around $31^{\circ} \mathrm{C}$ with diameter of thermocouple in $0.15 \mathrm{~mm}$. The system error became larger when the diameter of thermocouple increase. The results showed that the systematic error is around $39^{\circ} \mathrm{C}$ when the diameter of thermocouple was $0.5 \mathrm{~mm}$.In this test ,the 0.15 mm thermocouple was selected.

Table 1, Single cycle of data

\begin{tabular}{|c|c|c|c|c|}
\hline Rdg \# & Dote z Time (UTC+08.00) & Vollage & Unts & Annotation \\
\hline 274050 & $\operatorname{Jun} 24,201304: 14: 59.000$ & 1.11 & $\mathrm{mV}$ & \\
\hline 274051 & $\operatorname{Jun} 24.201304: 15,00000$ & 38515 & $\mathrm{mV}$ & \\
\hline 274052 & $\operatorname{Jun} 24,201304: 15,02000$ & 49.455 & $\mathrm{~m} v$ & \\
\hline 274053 & $\operatorname{Jun} 24,201304.15: 04.000$ & 6.945 & $\mathrm{mV}$ & \\
\hline 274054 & $\operatorname{Jun} 24,201304-15: 05,000$ & 6.18 & $\mathrm{mv}$ & \\
\hline 274055 & $\operatorname{Jun} 24,201304.15,08000^{\circ}$ & 8595 & $\mathrm{mV}$ & \\
\hline 274056 & $\operatorname{Jun} 24,201304: 15,10,000$ & 868 & $\mathrm{mV}$ & \\
\hline 274057 & $\operatorname{Jun} 24,201304.15 .12000$ & 586 & $\mathrm{mv}$ & \\
\hline 274058 & $\operatorname{Jun} 24,201304 \cdot 15: 14,000$ & 1.11 & $\mathrm{mV}$ & \\
\hline 274059 & $\operatorname{Jun} 24,201304: 15: 16,000$ & 38515 & $\mathrm{~m} v$ & \\
\hline 274060 & $\operatorname{Jun} 24,201304: 15: 18.000$ & 49.57 & $\mathrm{~m} v$ & \\
\hline
\end{tabular}
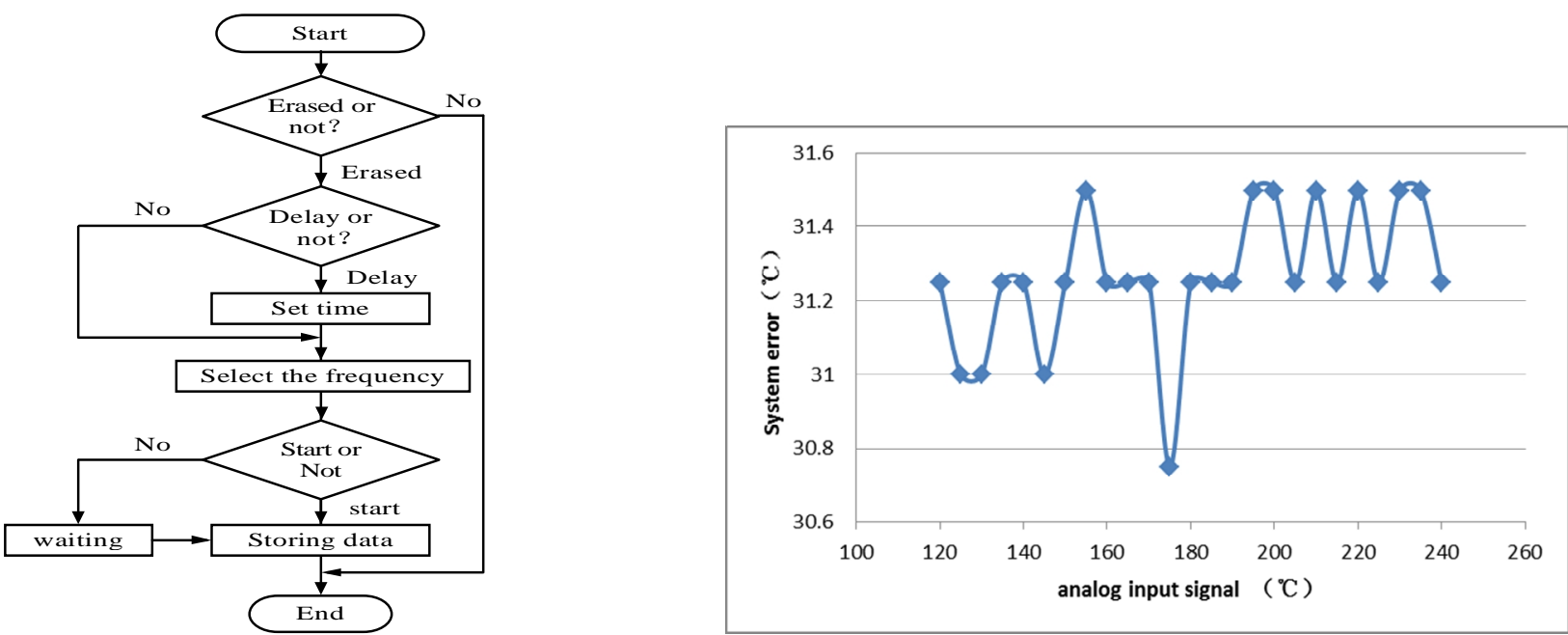

Fig.3. Program flow diagram of memory module Fig.4. Error calibration of measurement system

\section{Piston Temperature Measurement Test in CNG Engine}

There were five measurement points in the piston, they were point 1 at the center of the combustor surface, point 2 near the fillet of the combustor surface, point 3 near the fillet of the piston top, point 4 in the first ring groove and point 5 in the second ring groove, shown in fig.5.
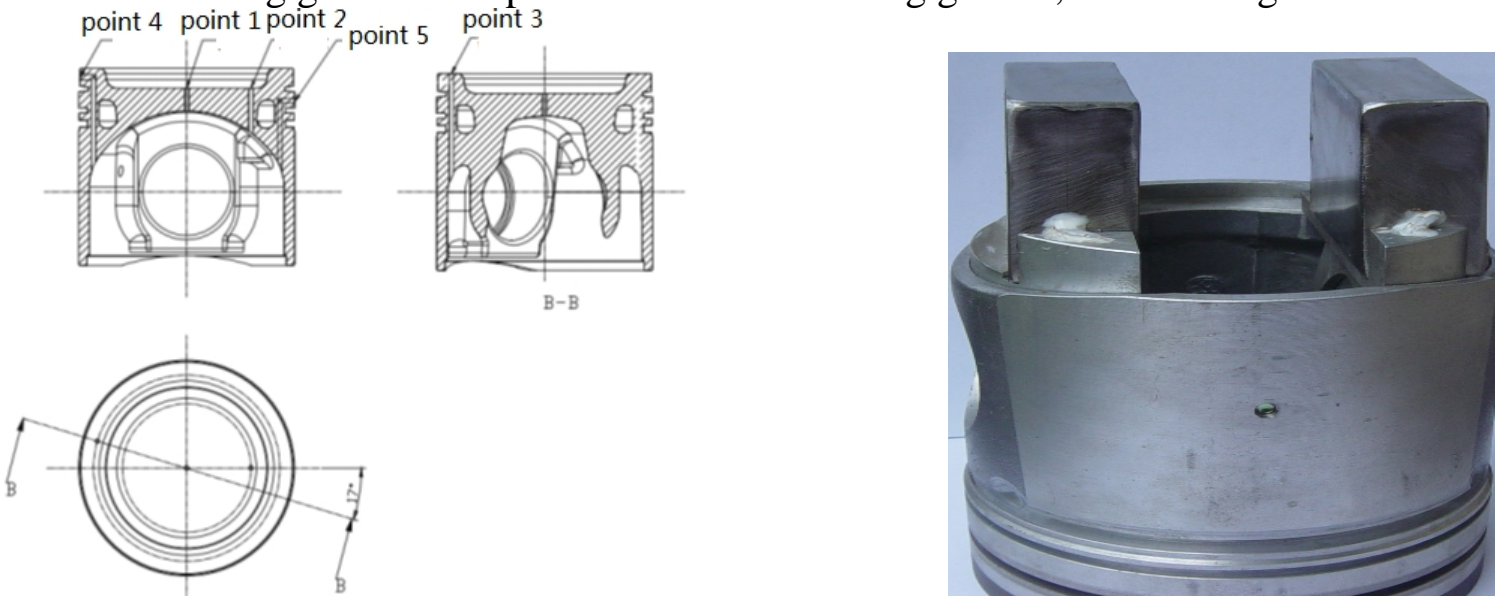

Fig. 5. The positions of five characteristic points. Fig.6. Assembly of the entire measurement system.

The type K thermocouples were encapsulated in the stop plugs with little conical degree by using thermal conductive Adhesive whose diameter had $2.4 \mathrm{~mm}$. There was a hole in the plug whose diameter had $1.2 \mathrm{~mm}$. The wire of the thermocouple was wrapped up by the oil-resistant tube whose work 
temperature was $260{ }^{\circ} \mathrm{C}$. In a short period, the plastic tube can be used on condition of $320{ }^{\circ} \mathrm{C}$. Glass fiber was filled between the wire and tube. The distance between the point of the thermocouple and the top face of a stop plug was ' $\delta$ ': $\quad \delta_{1}=1.0 \mathrm{~mm}, \delta_{2}=1.0 \mathrm{~mm}, \delta_{3}=1.0 \mathrm{~mm}, \delta_{4}=1.0 \mathrm{~mm}, \quad \delta_{5}=0.8 \mathrm{~mm}$.

As cold junction compensation of the thermocouple requires a constant temperature environment and components of the circuit board had temperature requirements, we took measures to prevent the circuit board from high temperature inside the engine. The thermostat box in our test had a four-story structure, two layers of $0.5 \mathrm{~mm}$-thick mica and two layers of insulation material. One layer of mica was put close to the circuit board and the other one was put close to the thermostat box, between which was the insulation material. The thermostat is made of $0.5 \mathrm{~mm}$-thick stainless steel. It was shown in Fig.6.

Measurement test was carried out on an EQRN375 engine, whose parameters were as follows: inter-cooling, oil cooling piston, inline six-cylinder CNG engine. Piston in the fifth cylinder was chosen as the measurement object, and the test was carried at speed of $1100 \mathrm{r} / \mathrm{min}, 1200 \mathrm{r} / \mathrm{min}, 1300 \mathrm{r} / \mathrm{min}$, $1500 \mathrm{r} / \mathrm{min}, 1700 \mathrm{r} / \mathrm{min}$ and $1900 \mathrm{r} / \mathrm{min}$ in this engine external characteristics, including maximum torque condition of speed at $1200 \mathrm{r} / \mathrm{min}$ and the maximum power condition point of speed at $1900 \mathrm{r} / \mathrm{min}$. The operating parameters of the engine were shown in table2.

Table2, the operating parameters of the engine

\begin{tabular}{|l|c|c|c|c|c|c|}
\hline Speed $(\mathrm{r} / \mathrm{min})$ & 1900 & 1700 & 1500 & 1300 & 1200 & 1100 \\
\hline Torque $(\mathrm{N} . \mathrm{m})$ & 1434 & 1478 & 1513 & 1529 & 1574 & 1565 \\
\hline Exhaust temperature $\left({ }^{\circ} \mathrm{C}\right)$ & 677.2 & 66 & 667.2 & 670.6 & 678.1 & 672.5 \\
\hline water temperature $\left({ }^{\circ} \mathrm{C}\right)$ & 85.7 & 85.5 & 85.7 & 86.6 & 87.7 & 88.3 \\
\hline oil temperature $\left({ }^{\circ} \mathrm{C}\right)$ & 95.9 & 93.8 & 94.2 & 93.6 & 94.1 & 94.2 \\
\hline
\end{tabular}

Fig.7 showed the average temperature of each point on the condition of $1900 \mathrm{r} / \mathrm{min}$ speed and maximum torque in three minutes and a half. Fig. 8 shows the average temperature of the five feature points on the condition of maximum torque points.

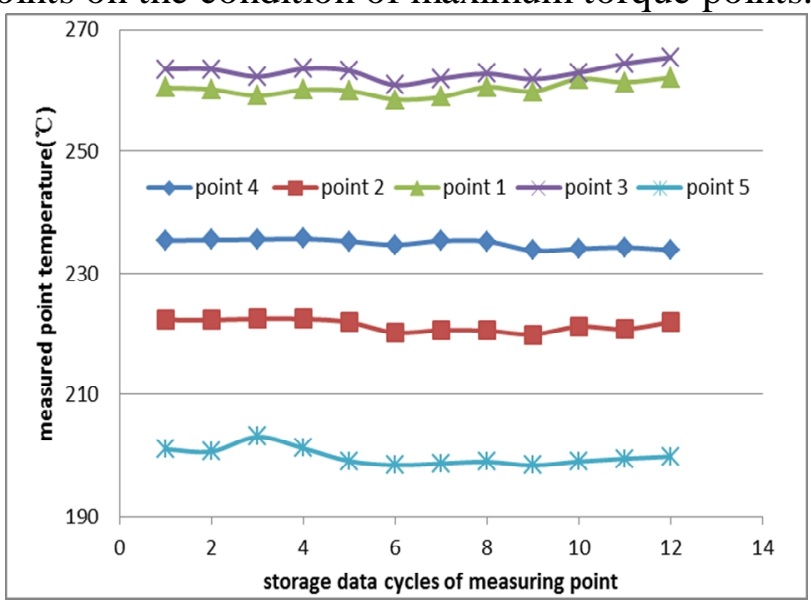

Fig.7.Temperature of 5 points on maximum power condition

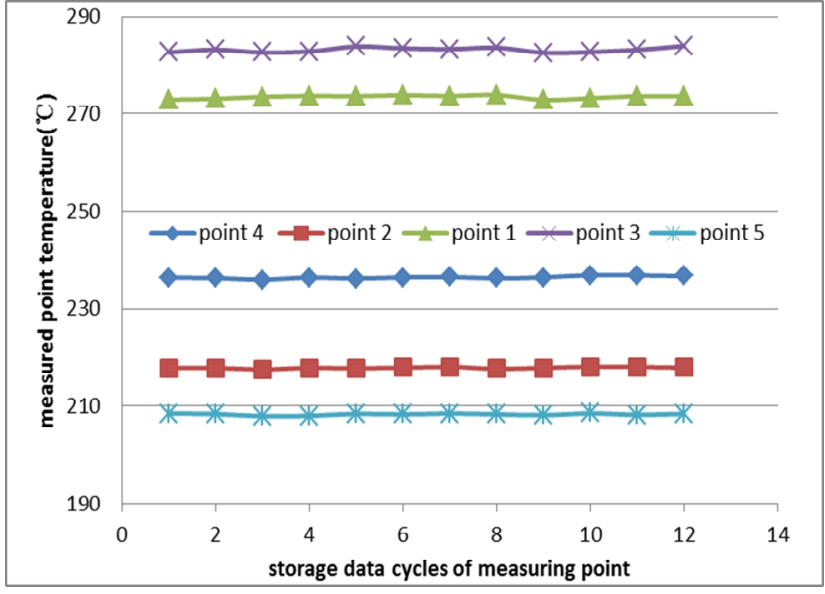

Fig.8.Temperature of 5 points on maximum torque condition

The temperature of the measurement points at the bottom of the combustion chamber is more different, and their temperature difference was about $38^{\circ} \mathrm{C}$, and the fluctuation of each measuring point are up to $5{ }^{\circ} \mathrm{Cand} 3{ }^{\circ} \mathrm{C}$; The smallest temperature fluctuation was found at the thermocouple of the second ring groove(feature point 5), the data of points had good consistency and the temperature waves within the limits permitted by Heat-frequency heating theory.

During the test, the temperature of each measuring pointat maximum torque condition was very smooth, with about $\pm 1^{\circ}$ Cof temperature fluctuations, the overall temperature is higher than the maximum power point conditions. The temperature gradient between the measuring point hadn't changed. The temperature of each operating point of the outer characteristics was shown in Fig.9.

From figure 9, temperature trends of each measuring point were different, with the speed increased. The temperature of point 1 , point 3 , and point 5 rose highest at the maximum torque point maximum, and then slowly declined. The temperature of point 4 laxly increased as the speed was increased. The temperature of point 2 remained constant, with speed rising. 


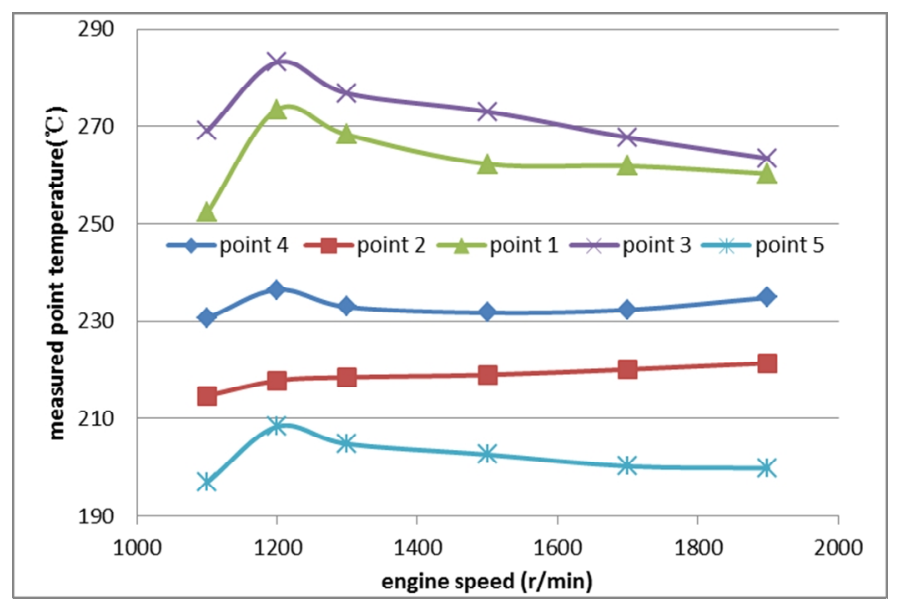

Fig.9. Measurement point temperature at different speeds

\section{Conclusions}

The temperature measurement device based on voltage logger had high accuracy and reliability, and was used on variable working condition. Used thermostat design, the measurement system could stably work at $120^{\circ} \mathrm{C}$ and had an accuracy of $\pm 1{ }^{\circ} \mathrm{C}$.

The piston temperature change rule of EQRN375 CNG engine was described. The results also show that the top land had the highest temperature, and it reaches $284^{\circ} \mathrm{C}$ at $1200 \mathrm{rpm}$. Especially the temperature in the first ring groove could reach $209^{\circ} \mathrm{C}$, which was about the carbonization temperature.

\section{References}

[1] Naoya Kato and Michiyasu Moritsugu, Takashi Shimura and Jun Matsui, "Piston Intermiterender Inductiver Kopplu Temperature Measuring Technology Using Electro magnetic Induction," SAE 2001-01-2027, P.1890-1896

[2] Julian T. Kashdan, Gilles Bruneaux, et al. Laser-Induced Phosphorescence Measurements of Combustion Chamber Surface Temperature on a Single-Cylinder Diesel Engine. SAE International, 2011-01-2049

[3] Daniel P. Madison, Scott A. Miers, Glen L. Barna, et al. Comparison of Piston Temperature Measurement Methods: Templugs Versus Wireless Telemetry with Thermocouples. Proceedings of the ASME 2012 Internal Combustion Engine Divison Fall Technical Conference, ICEF 2012-92184

[4] Orgun Guralp, Mark Hoffman, Dennis Asssanis, et al. Thermal Characterization of Combustion Chamber Deposits on the HCCI Engine Piston and Cylinder Head Using Instantaneous Temperature Measurements. SAE International, 2009-01-0668

[5] Yan peng Yuan, Zhiyong Zhou, "A study on stored sesting and seasuring system for the temperature field of a piston with small diameter," Vehicles and power technology, N0.4, p7-11, 2004, in China .K. 